\title{
APLIKASI PERHITUNGAN TUNJANGAN KINERJA PEGAWAI DI BADAN PUSAT STATISTIK KABUPATEN BANJAR
}

\author{
Adani Dharmawati \\ Fakultas Teknologi Informasi \\ Universitas Islam Kalimantan Muhammad Arsyad Al Banjari Banjarmasin \\ Email : adani.dharmawati@gmail.com
}

\begin{abstract}
Abstrak
Pada Badan Pusat Statistik Kabupaten Banjar, perhitungan tunjangan kinerja pegawai sudah menggunakan bantuan komputer, yaitu dengan Microsoft Office Excel. Namun dalam pelaksanaannya masih terdapat kekurangan, yaitu berakibat pada jumlah file yang sangat banyak, adanya pemborosan kapasitas memori, dan memungkinkan adanya kesalahan pengetikan dalam proses perhitungan. Untuk itulah diperlukan suatu aplikasi yang dapat menunjang kebutuhan akan penyelesaian masalah, yakni aplikasi perhitungan dan pengolahan data terkomputerisasi. Dengan adanya aplikasi perhitungan dan pengolahan data untuk tunjangan kinerja pegawai secara terkomputerisasi maka perhitungan dan pengolahan data untuk tunjangan kinerja pegawai dapat terkelola dengan baik dan memudahkan dalam pengendalian arus informasi. Dan juga peran komputer dapat membantu dalam pekerjaan tugastugasnya secara efektif dan efisien, sehingga kualitas kerja dapat ditingkatkan.
\end{abstract}

Keywords: Badan Pusat Statistik, tunjangan, kinerja pegawai 


\section{PENDAHULUAN}

Berdasarkan Peraturan Kepala Badan Pusat Statistik Nomor 76 Tahun 2012 menyatakan Tunjangan kinerja diberikan kepada pegawai yang mempunyai tugas/pekerjaan/jabatan tertentu, selain diberikan penghasilan sesuai ketentuan peraturan perundang-undangan, diberikan Tunjangan Kinerja setiap bulan [1].

Tunjangan Kinerja diberikan dengan memperhitungkan capaian kinerja Pegawai setiap bulannya. Nominal Tunjangan Kinerja Pegawai didapat dari perhitungan antara Tunjangan Kinerja dikalikan dengan Capaian Kinerja Pegawai (CKP) [2].

Pada Badan Pusat Statistik Kabupaten Banjar, perhitungan tunjangan kinerja pegawai sudah menggunakan bantuan komputer, yaitu dengan Microsoft Office Excel. Namun dalam pelaksanaannya masih terdapat kekurangan, yaitu setiap pegawai mempunyai satu file tiap bulannya, terdapat perulangan daftar kegiatan pada setiap file, dan dalam proses perhitungan Capaian Kinerja Pegawai (CKP) masih ada penginputan secara manual yaitu pada total MAK (Mutu Angka Kredit) pegawai. Ini berakibat pada jumlah file yang sangat banyak, adanya pemborosan kapasitas memori, dan memungkinkan adanya kesalahan pengetikan dalam proses perhitungan. Pada saat pencarian data juga terdapat kendala, yaitu perlu membuka satu per satu file dan mencari nama pegawai di tiap folder bulanan, hal ini memakan waktu yang cukup lama.

Umumnya delphi hanya digunakan untuk pengembangan aplikasi desktop, enterprise berbasis database dan program-program kecil. Namun karena pengembangan Delphi yang semakin pesat dan bersifat general purpose, bahasa pemprograman ini mampu digunakan untuk berbagai jenis pengembangan software dan Delphi juga disebut sebagai pelapor perkembangan RatTool (Rapid Apllication Development) tahun 1995. Sehingga banyak orang yang mulai mengenal dan menyukai bahsa pemprograman yang mulai mengenal dan menyukai bahasa pemprograman yang bersifat VCL (Visual Component Library) [3].

Microsoft Office Access adalah program pengolahan database yang sangat populer.
Program ini merupakan salah satu program aplikasi yang berada dalam keluarga Microsoft

Adapun dalam melakukan pengumpulan data digunakan Office. Saat ini cukup banyak pengguna Microsoft Access yang hanya menggunakan program ini untuk membuat table databse, padahal dalam Microsoft Access tersedia banyak fasilitas yang dapat digunakan untuk memaksimalkan pembuatan laporan yang dibuat dalam bentuk Query, Form, atau Report. Salah satu fasilitas yang disediakan Microsoft Access adalah fungsi. Microsoft Access menyediakan banyak fungsi yang dikelompokkan beberapa kategori untuk melakukan proses kalkulasi data [4].

Untuk itulah diperlukan suatu aplikasi yang dapat menunjang kebutuhan akan penyelesaian masalah, yakni aplikasi perhitungan dan pengolahan data terkomputerisasi. Dengan adanya aplikasi perhitungan dan pengolahan data untuk tunjangan kinerja pegawai secara terkomputerisasi maka perhitungan dan pengolahan data untuk tunjangan kinerja pegawai dapat terkelola dengan baik dan memudahkan dalam pengendalian arus informasi. Dan juga peran komputer dapat membantu dalam pekerjaan tugas-tugasnya secara efektif dan efisien, sehingga kualitas kerja dapat ditingkatkan.

Aplikasi ini diharapkan mampu untuk membantu dalam proses perhitungan tunjangan kinerja pegawai di Badan Pusat Statistik Kabupaten Banjar.

\section{METODE PENELITIAN}

Populasi dalam penelitian ini yaitu pegawai Badan Pusat Statistik Kabupaten Banjar yang menjadi info utama dalam pembuatan aplikasi perhitungan tunjangan kinerja pegawai. Jumlah elemen sampel yang digunakan dalam penelitian ini berjumlah 6 orang pegawai Badan Pusat Statistik Kabupaten Banjar. Terdiri dari 3 orang kepala seksi, dan 3 orang Koordinator Statistik Kecamatan (KSK).

Data yang digunakan dalam penelitian ini berupa data primer dan data sekunder. Data primer berupa data yang diperoleh secara langsung dari Badan Pusat Statistik Kabupaten 
Banjar. Dan data sekunder berupa data yang diperoleh pada saat dilakukan penelitian. beberapa cara antara lain:

a. Observasi

Yaitu metode untuk mendapatkan data dengan melakukan pengamatan langsung pada Badan Pusat Statistik Kabupaten Banjar. Dari observasi ini dapat diketahui proses perhitungan tunjangan kinerja pegawai yang selama ini dilakukan.

b. Studi Pustaka

Studi pustaka dilakukan dengan mengumpulkan data yang dilakukan dengan mencari literature, data-data dari bukubuku, dan kepustakaan lainnya yang berhubungan dengan penelitian ini.

c. Wawancara

Yaitu melakukan tanya jawab terhadap Kepala Seksi Statistik Distribusi yang bertanggung jawab terhadap perhitungan dan pendataan tunjangan kinerja pegawai di dari Badan Pusat Statistik Kabupaten Banjar.

\section{Implementasi Sistem}

\section{a. Form Login}

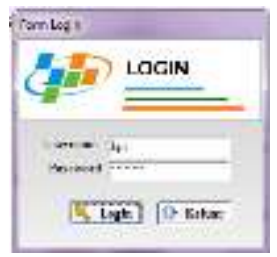

Gambar 1. Form Login

Pada saat aplikasi pertama kali dijalankan, pengguna aplikasi akan diperhadapkan pada form login dan diminta untuk memasukkan username dan password yang telah ditentukan.

\section{b. Form Menu Utama}

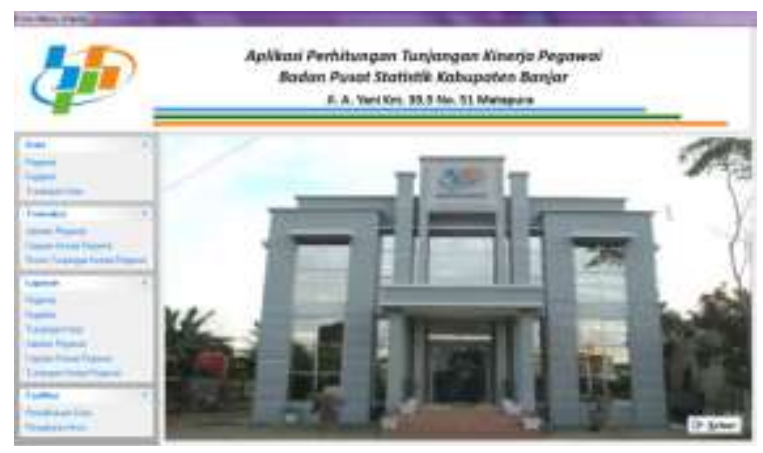

Gambar 2. Form Menu Utama

Menu utama terdiri dari terdapat 5 menu, yaitu data, transaksi, laporan, fasilitas dan keluar.

\section{c. Form Data Pegawai}

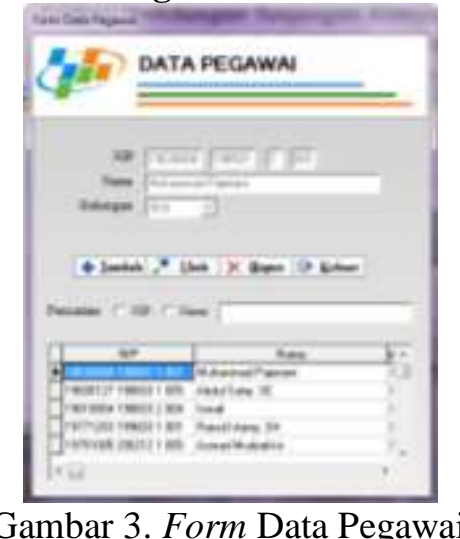

Pada form Data Pegawai digunakan untuk mengisi data pegawai, seperti NIP, nama, dan golongan.

\section{d. Form Data Kegiatan}

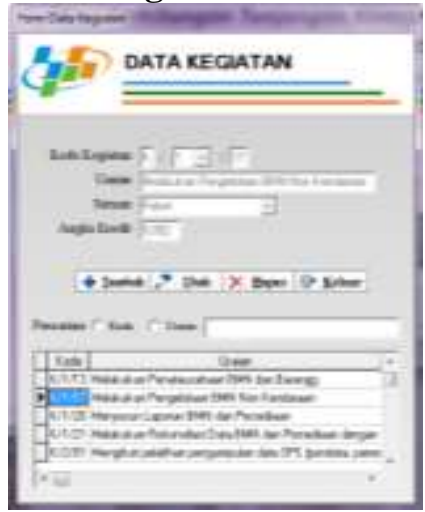

Gambar 4. Form Data Kegiatan 
Pada form Data Kegiatan digunakan untuk mengisi data kegiatan, seperti kode kegiatan, uraian, satuan, dan angka kredit.

\section{e. Form Data Tunjangan Kerja}

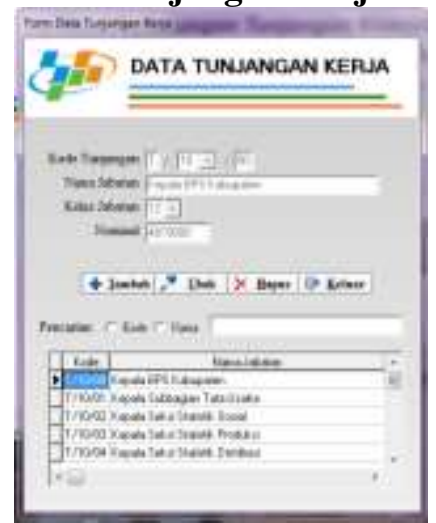

Gambar 5. Form Data Tunjangan Kerja

Pada form Data Tunjangan Kerja digunakan untuk mengisi data tunjangan kerja, seperti kode tunjangan, nama jabatan, kelas jabatan, dan nominal.

\section{f. Form Jabatan Pegawai}

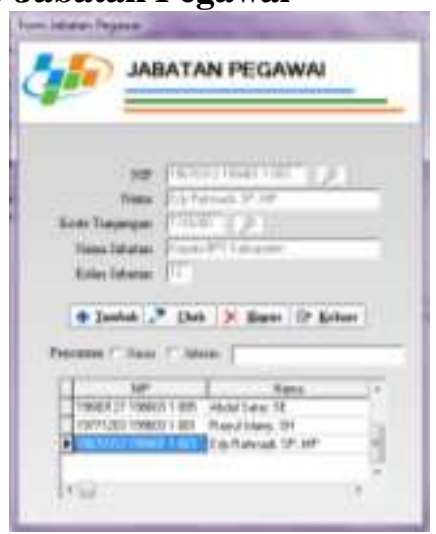

Gambar 6. Form Jabatan Pegawai

Pada form Jabatan Pegawai digunakan untuk mengisi data jabatan pegawai, seperti NIP, nama, kode tunjangan, nama jabatan, dan kelas jabatan.

\section{g. Form Capaian Kinerja Pegawai}

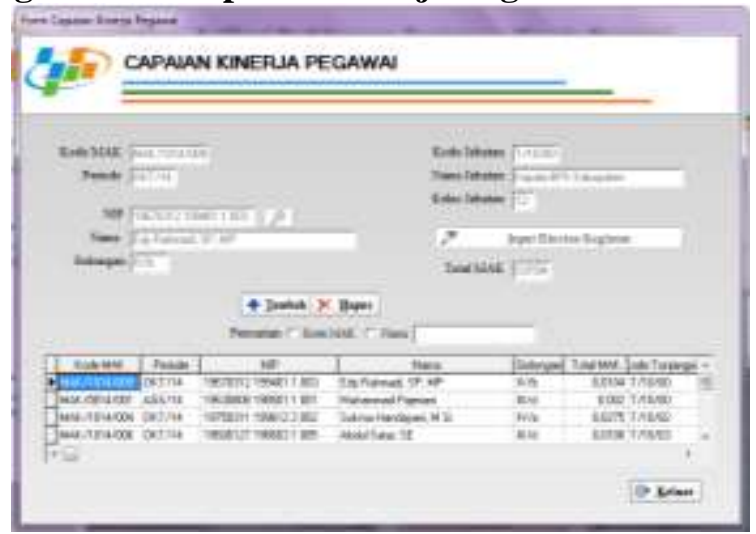

Gambar 7. Form Capaian Kinerja Pegawai

Pada form Capaian Kinerja Pegawai digunakan untuk mengisi data capaian kinerja pegawai, seperti kode MAK, periode, NIP, nama, golongan, kode jabatan, kelas jabatan, dan total MAK.

\section{h. Form Rincian Kegiatan}

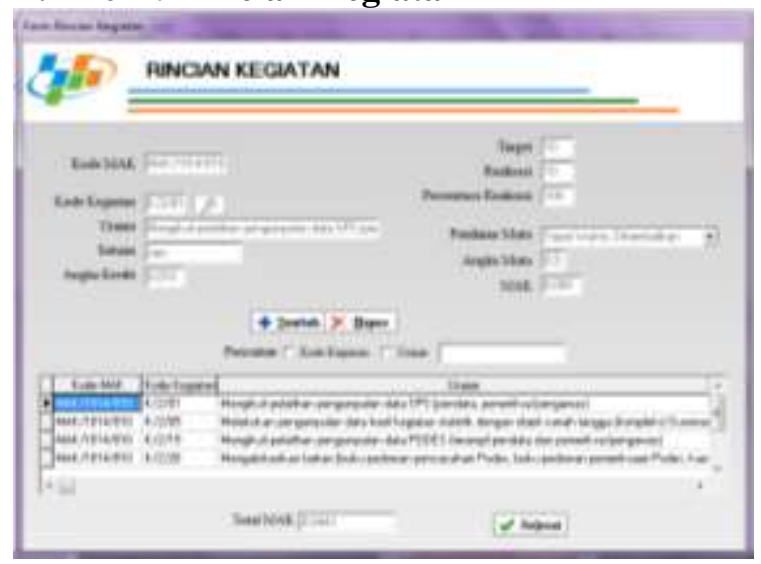

Gambar 8. Form Rincian Kegiatan

Pada form rincian kegiatan digunakan untuk mengisi data rincian kegiatan, seperti kode MAK, kode kegiatan, uraian, satuan, angka kredit, target, realisasi, persentase realisasi, penilaian mutu, angka mutu, Mutu Angka Kredit (MAK) dan Total Mutu Angka Kredit (MAK). 


\section{i. Form Proses Tunjangan Kinerja Pegawai}

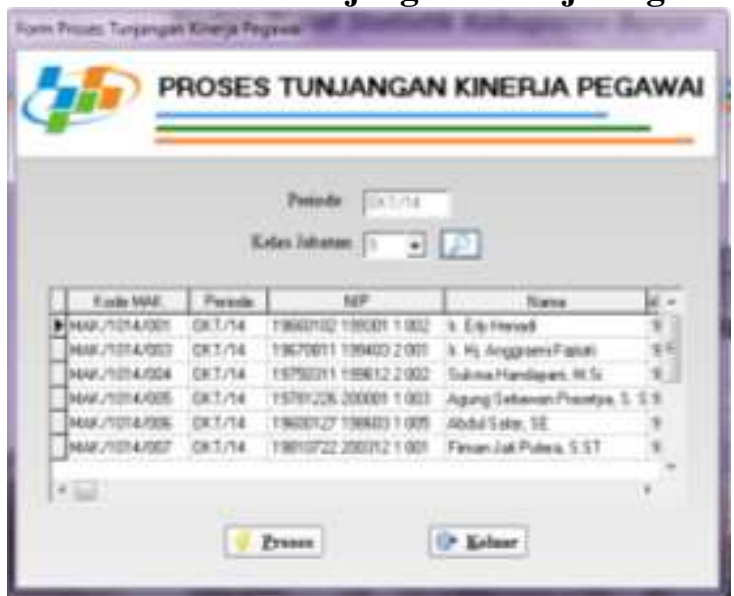

Gambar 9. Form Proses Tunjangan Kinerja Pegawai

Pada form tunjangan kinerja pegawai digunakan untuk memproses perhitungan tunjangan kinerja pegawai, dengan mengisi periode dan kelas jabatan terlebih dahulu.

\section{j. Form Laporan Data Pegawai}

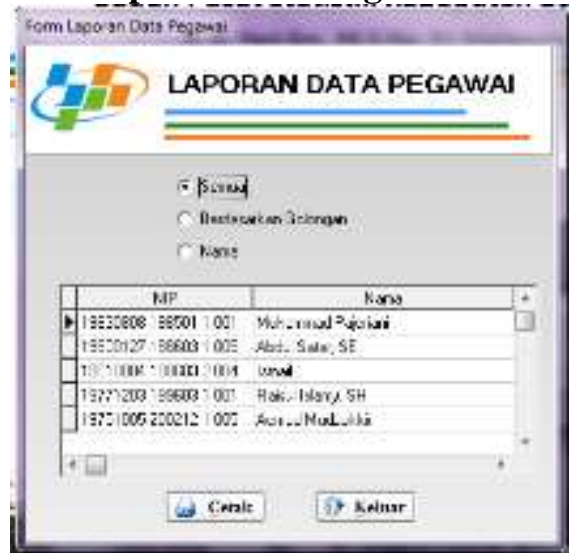

Gambar 10. Form Laporan Data Pegawai

Form laporan data pegawai adalah form yang terdapat pada menu laporan. Laporan ini menampilkan semua data pegawai yaitu: NIP, nama dan golongan.

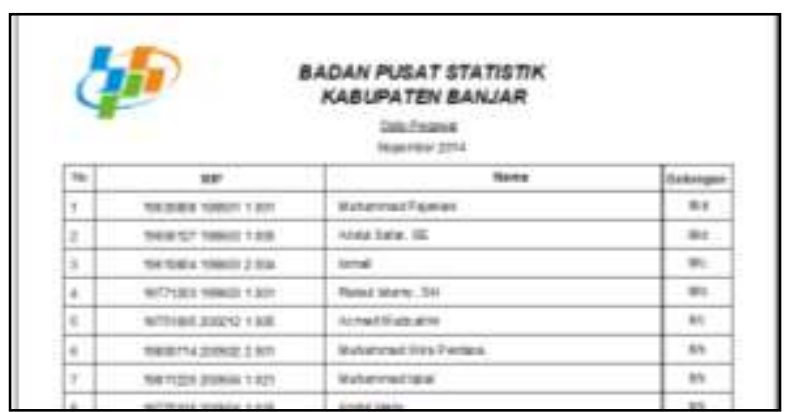

Gambar 11. Hasil Laporan Data Pegawai

k. Form Laporan Data Kegiatan

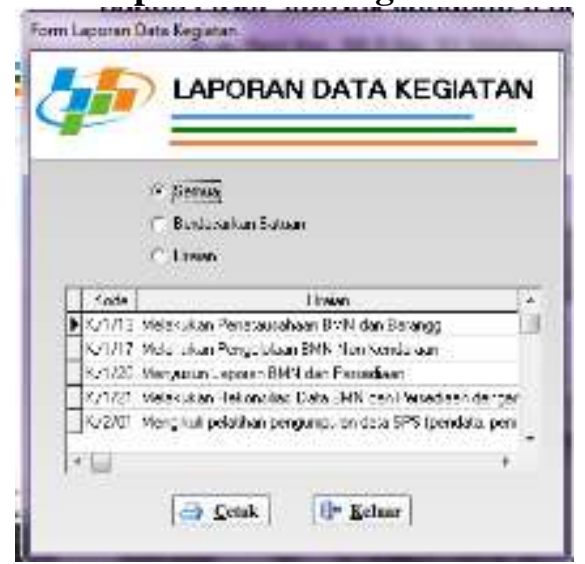

Gambar 12. Form Laporan Data Kegiatan

Form laporan data kegiatan adalah form yang terdapat pada menu laporan. Laporan ini menampilkan semua data kegiatan yaitu: Kode kegiatan, uraian, satuan dan angka kredit.

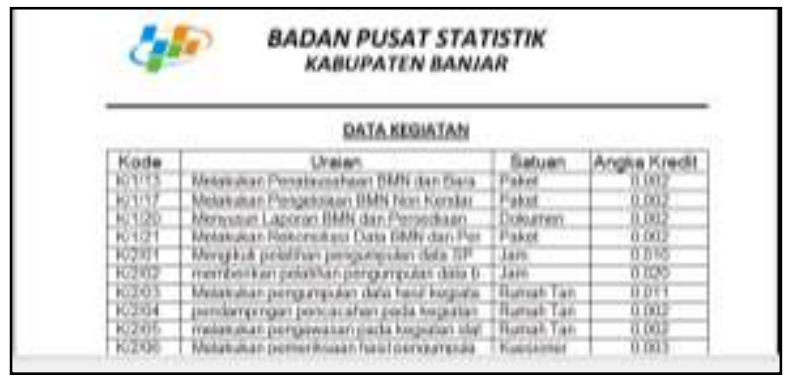

Gambar 13. Hasil Laporan Data Kegiatan 
1. Form Laporan Data Tunjangan Kerja

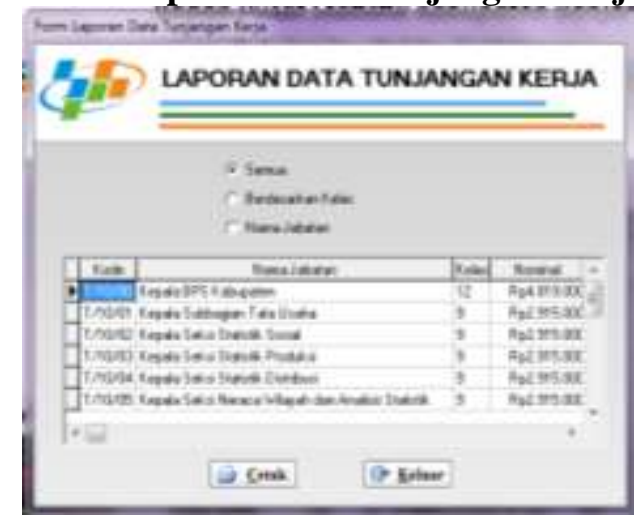

Gambar 14. Form Laporan Data Tunjangan Kerja

Form laporan data tunjangan kerja adalah form yang terdapat pada menu laporan. Laporan ini menampilkan semua data tunjangan kerja yaitu: Kode tunjangan, nama jabatan, kelas jabatan dan nominal tunjangan.

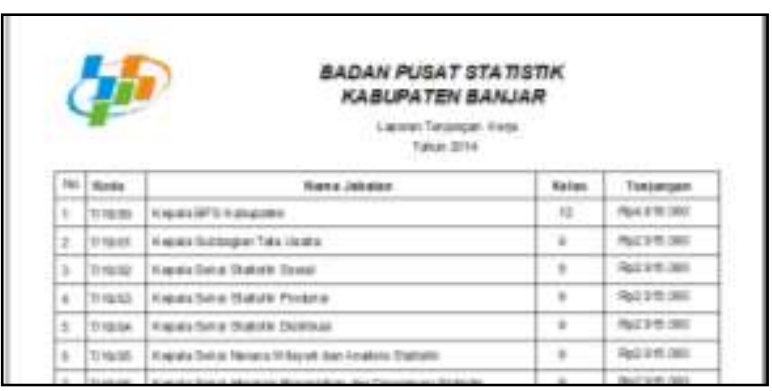

Gambar 15. Hasil Laporan Data Tunjangan

m. Form Laporan Data Jabatan Pegawai

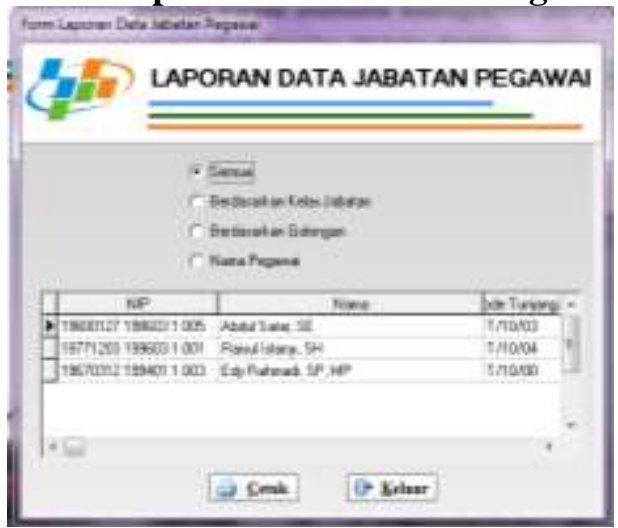

Gambar 16. Form Laporan Data Jabatan Pegawai
Form laporan data jabatan pegawai adalah form yang terdapat pada menu laporan. Laporan ini menampilkan semua data jabatan pegawai yaitu: NIP, nama, kode tunjangan, nama jabatan, dan kelas jabatan.

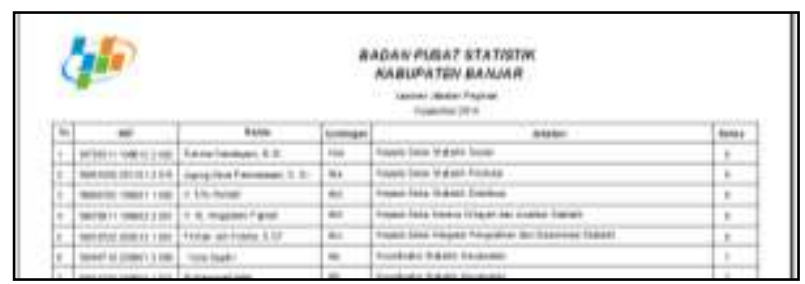

Gambar 17. Hasil Laporan Data Jabatan Pegawai

n. Form Laporan Capaian Kinerja Pegawai

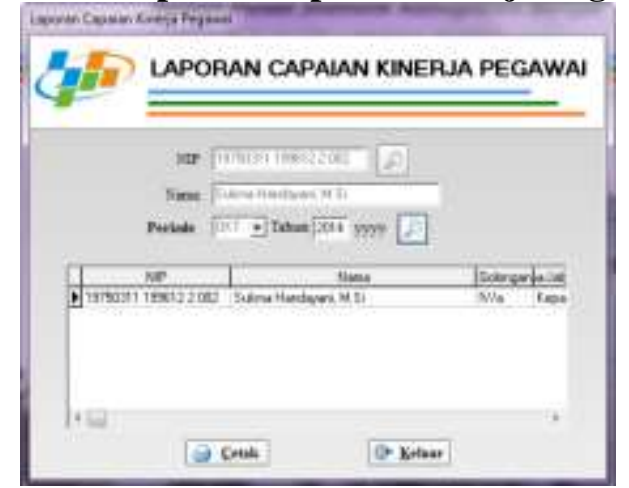

Gambar 18. Form Laporan Capaian Kinerja Pegawai

Form laporan capaian kinerja pegawai adalah form yang terdapat pada menu laporan. Laporan ini menampilkan semua rincian capaian kinerja pegawai tiap bulannya, yaitu: NIP, nama pegawai, golongan, periode, rincian kegiatan, uraian, target, realisasi, Mutu Angka Kredit (MAK), Total Mutu Angka Kredit (Total MAK), Capaian Kinerja Pegawai dan Tunjangan Kinerja Pegawai. 


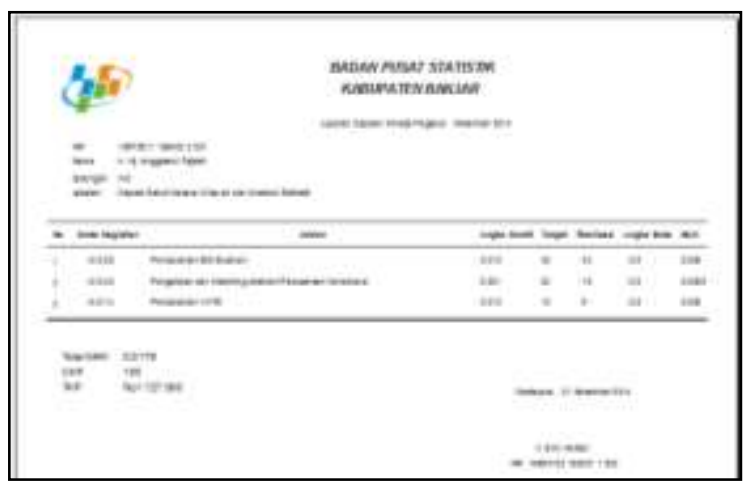

Gambar 19. Hasil Laporan Capaian Kinerja Pegawai

\section{o. Form Laporan Tunjangan Kinerja Pegawai}

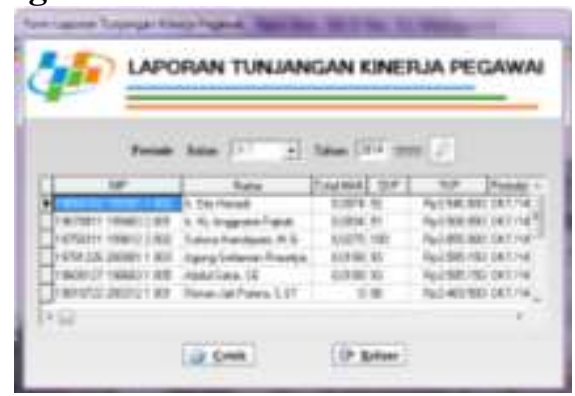

Gambar 20. Form Laporan Tunjangan Kinerja Pegawai

Form laporan tunjangan kinerja pegawai adalah form yang terdapat pada menu laporan. Laporan ini menampilkan semua data tunjangan kinerja pegawai tiap bulannya, yaitu: NIP, nama pegawai, Total Mutu Angka Kredit (Total MAK), Capaian Kinerja Pegawai dan Tunjangan Kinerja Pegawai.

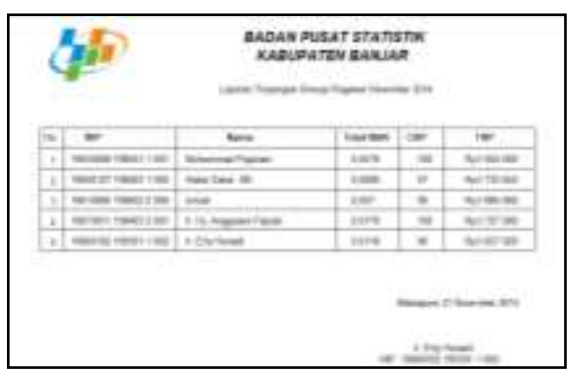

Gambar 21. Hasil Laporan Tunjangan Kinerja Pegawai

\section{p. Form Pengaturan Akun}

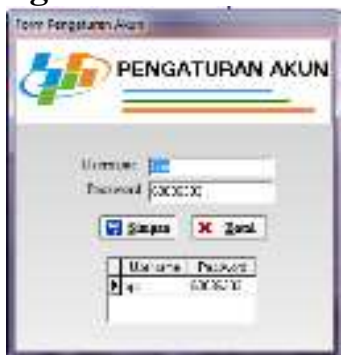

Gambar 22. Form Pengaturan Akun

Pada form pengaturan akun digunakan untuk mengubah akun pengguna, seperti password dan username.

\section{q. Form Pemeliharaan Data}

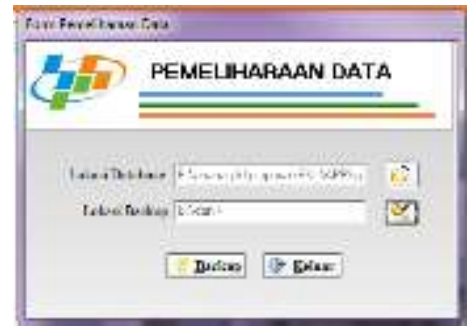

Gambar 23. Form Pemeliharaan Data

Form Pemeliharaan Data adalah form yang digunakan untuk membackup database yang ada pada aplikasi Perhitungan Tunjangan Kinerja Pegawai. Sebelum melakukan backup, kita harus menentukan direktori tujuan dimana kita akan meletakkan file backup kita. File backup berupa tabel-tabel yang ada pada Aplikasi Perhitungan Tunjangan Kinerja Pegawai.

\section{Kesimpulan}

Dengan adanya aplikasi perhitungan dan pengolahan data untuk tunjangan kinerja pegawai secara terkomputerisasi maka perhitungan dan pengolahan data untuk tunjangan kinerja pegawai dapat terkelola dengan baik dan memudahkan dalam pengendalian arus informasi.

Dapat disimpulkan bahwa aplikasi yang dibangun sudah sesuai dengan tujuan yaitu memberi kemudahan dalam perhitungan tunjangan kinerja pegawai agar menjadi lebih mudah, serta dapat memberikan informasi yang lebih cepat dengan menggunakan aplikasi berbasis teknologi komputer. Serta dapat 
membantu dalam menyusun laporan Capaian Kinerja Pegawai dan Tunjangan Kinerja Pegawai di Badan Pusat Statistik Kabupaten Banjar.

Untuk penelitian selanjutnya diharapkan mengembangkan aplikasi perhitungan tunjangan kerja kinerja pegawai di Badan Pusat Statistik Kabupaten Banjar ini dapat dilanjutkan sampai perhitungan tunjangan kinerja yang didapat pegawai berdasarkan tingkat pencapaian kinerja pegawai, tingkat kehadiran menurut hari dan jam kerja, dan ketaatan pada kode etik dan disiplin pegawai. Disamping itu diharapkan adanya perbaikan dari segi desain aplikasi maupun dengan penambahan fitur lainnya sehingga dapat menampilkan aplikasi yang lebih baik dari yang sebelumnya.

\section{Referensi}

[1] Suryamin. (2012). Peraturan Kepala Badan Pusat Statistik Nomor 76 Tahun 2012. Jakarta: Badan Pusat Statistik.

[2] Biro Kepegawaian BPS. (2013). Penjelasan Penghitungan Tunjangan Kinerja 2013. Jakarta: BPS.

[3] Rahman, A., \& Akhmad, J. (2013). Aplikasi persetujuan pasang baru listrik wilayah Banjarbaru. Banjarbaru: Stmik Banjarbaru.

[4] MADCOMS, L. (2005). Rumus dan Fungsi Pada Microsoft Access. Yogyakarta: Andi. 